\title{
Review \\ Bench-to-bedside review: The MET syndrome - the challenges of
researching and adopting medical emergency teams
} Augustine Tee, Paolo Calzavacca, Elisa Licari, Donna Goldsmith and Rinaldo Bellomo

Department of Intensive Care and Department of Surgery (Melbourne University), Austin Hospital, Studley Road, Heidelberg, Melbourne, Victoria 3084, Australia

Corresponding author: Rinaldo Bellomo, rinaldo.bellomo@austin.org.au

Published: 23 January 2008

This article is online at http://ccforum.com/content/12/1/205

(C) 2008 BioMed Central Ltd
Critical Care 2008, 12:205 (doi:10.1186/cc6199)

adverse events, with an overall hospital mortality of $5 \%$ to $8 \%$ [1-3]. Importantly, an estimated $37 \%$ of these events may be preventable [3]. Multiple studies from Europe, the US, and Australia have also confirmed deficiencies in the way hospitals and 'traditional' models of care respond to acute illness in the wards [4-7]. One deficiency of the hospital system's approach to acute illness is the problem of 'failure to rescue' [8]: failure to deliver rapid and competent care to an acutely ill ward patient. Traditionally, hospitals have left such rapid responses to either the parent unit or cardiac arrest teams. Unfortunately, the parent unit doctors are often unable to attend the patient rapidly or are not specifically or sufficiently trained in acute resuscitation [4-7]. Although cardiac arrest teams have been around for decades, they often arrive at the end of the disease cascade, are unsuccessful in greater than $85 \%$ of patients, and patients so treated may survive the arrest but carry a high risk of hypoxic brain injury [9-11]. These observations suggest that earlier recognition of disease progression provides the opportunity to avert major adverse events in many cases. In others, it provides the opportunity to put in place a terminal care plan that prevents unnecessary interventions and an undignified death.

Early recognition of an 'at-risk' situation is important in ensuring patient safety. Physiological warning signs (instability) of impending cardiac arrest have been repeatedly demonstrated to be common $[6,8-10]$ and to precede such events by several hours, with $60 \%$ to $84 \%$ of cardiopulmonary arrest patients showing physiological instability within 6 to 8 hours of the event $[12,13]$. However, in traditional systems, the hospital's response is often late and inadequate [12-24]. The outcome of this approach has not improved in 50 years. Clear evidence of inadequate ward care was provided by a study from the UK [6] which found that, prior to intensive care unit (ICU) admission, suboptimal management of oxygen therapy,

ICU = intensive care unit; MERIT = Medical Emergency Response Improvement Team; MET = medical emergency team; RRS = rapid response system. 
airway, breathing, circulation, and monitoring occurred in over half of patients. These errors were essentially due to the failure to apply or appreciate the need for basic resuscitation measures. Major causes of suboptimal care included failure of organisation, failure to appreciate clinical urgency, and failure to seek advice [6]. In summary, there is much evidence that 'failure to rescue' is common in patients at risk for major adverse events. There is also evidence that failure to appreciate the clinical urgency of situations is common, that the knowledge and skills to deal with such situations are limited among ward doctors and nurses, and that, in most patients, there are warning signs for a long enough period to allow appropriate action to be taken.

\section{Critical care for the critically ill anywhere in the hospital}

The concept of rapid and early rescue is well established in various fields of medicine, especially in trauma, cardiology, and, more recently, severe sepsis and septic shock [25-27]. It would make sense to apply these concepts to critical illness in general, wherever it may occur in the wards, and to use an RRS to deliver early intervention by specifically trained teams. In this regard, it is important to realise that, in most hospitals, the expertise exists to rapidly deliver the skills and knowledge to the bedside when necessary to deal with critical illness. Critical care physicians and critical care nurses can theoretically deliver such expertise anywhere in the hospital within minutes.

The field of critical care medicine has made considerable progress in improving outcomes of critically ill patients. Given that most acute illness develops through stages of deterioration, the logical step surely would be to bring intensive care equipment and expertise to any acutely ill patient, irrespective of location within the hospital, in what has been described as creating a 'critical care system without walls' [28]. The medical emergency team (MET) brings this expertise to the patient in a timely manner and supplies the 'efferent arm' of this process of identification of at-risk patients and rapid delivery of appropriate care, designated recently as the rapid response system (RRS) [29].

Because the care of critically ill patients is their core specialty competency, intensive care doctors and nurses are ideally placed to provide immediate care to patients who are critically ill: they are acute illness specialists. The value of specialists in expert management of specific disease conditions is widely accepted. Specialists are so named because they are trained with particular skills and in-depth knowledge. It would seem illogical for inadequately trained doctors to treat acutely ill patients instead of critical care physicians and nurses being responsible for their management [30].

\section{Common sense or science}

The concepts presented above seem, at face value, to simply represent common sense. However, in an era of 'evidence- based medicine', the efficacy of the MET and utility of the RRS have been criticised for lacking sufficient high-quality evidence in the form of randomised controlled trials. Metaanalytical techniques have been used to demonstrate the weakness of such evidence [31,32]. For example, in a recent meta-analysis by Winters and colleagues [32], although the respective relative risks (95\% confidence intervals) for hospital mortality and cardiac arrest were 0.76 (0.39 to 1.48) and 0.94 ( 0.79 to 1.13 ) (suggesting a benefit), the authors concluded that the heterogeneity of the studies and wide confidence interval suggest that adopting RRS as a standard of care is premature and possibly wrong.

In our opinion, however, there are unique issues surrounding RRS which need to be taken into account when interpreting the available evidence. First, these systems are not simple tablets whose efficacy or effectiveness can be tested in double-blind randomised controlled trials [33]. Second, these systems are complex human activities. They require consideration of several important anthropological, organisational, political, logistic, and administrative aspects [29]. These aspects profoundly affect the implementation, performance, and efficacy of such systems. Third, acceptance of the cultural changes associated with the introduction of RRS requires time, making early assessment of such systems flawed and non-representative of their later performance $[29,34]$. Accordingly, the challenges surrounding the implementation of such systems require detailed discussion.

\section{The challenges of implementing rapid response systems}

Even when the concept of RRS is believed to be advantageous, the actual implementation entails overcoming a myriad of barriers: political, financial, educational, cultural, logistic, anthropological, and emotional (Table 1). Some of these challenges are particularly important to consider.

\section{Rapid response system breaks with 'tradition'}

The culture of ward doctors managing acutely unwell patients is changed by the introduction of RRS. We have seen this at our institution, where ICU doctors and nurses are no longer viewed as experts confined to the 'ivory tower' of the ICU but are now constantly assessing and helping to treat 'at-risk' patients in general wards [35]. This paradigm shift in our hospital culture and medical practice has changed how the roles of ICU and hospital doctors and nursing staff are being viewed. Nevertheless, allegiance to the traditional approach of initially calling the parent medical unit doctors when there are objective early signs of clinical deterioration is difficult to eradicate: $72 \%$ of nurses surveyed continue to choose to call the parent unit first, despite several years of RRS operation [36]. It is an extraordinary challenge to change 'culture'.

\section{Rapid response systems challenge medical 'power'}

The MET patient is created by the environment and the disease and not by the disease per se. This implies a 
Table 1

Implementation difficulties with the rapid response system
Difficulties of implementing the rapid response system
Breaks from traditional hierarchy of medical consults
Challenges medical 'power'
Gives ward nurses more independent authority
Perceived shame in calling the MET
Inefficient ward monitoring of physiological signs
Delay in activating the MET
Non-clinical challenges
logistics
financial
educational
cultural
emotional
anthropological
political

MET, medical emergency team.

mismatch between resources and needs as a component of the syndrome. The arrival of the MET brings a critical care environment to the bedside. In a sense, when an MET syndrome develops, it could be argued that both the hospital and the patient are 'sick' [37]. Occasionally, errors that underlie the development of the MET syndrome naturally surface during an MET review [38]. This often causes parent medical unit doctors and ward nurses to worry about criticism. It is important to emphasise that the MET service is 'hospital policy' and that no hospital staff should be reprimanded for calling the MET. Similarly, it is vital to reiterate that the MET intervention does not represent an attempt by the ICU staff to take over patient management [35]. Despite these assurances, many doctors remain uncomfortable over the perceived loss of control and the fact that nurses can activate the MET without requiring permission from them. Ignoring these problems and not seeking to reassure medical staff is likely to increase the chance of failure of an RRS.

\section{Rapid response systems give ward nurses more power}

As nurses are in direct patient contact most of the time, they also need and call an MET most. Surveys have shown that a majority of nurses welcome the availability of an MET service, with 84\% feeling that it improves their work environment and $65 \%$ considering it a factor when seeking a new job in an institution $[39,40]$. The MET enables the nurse to exercise independent judgement and to call for immediate assistance should the patient fulfill a predetermined set of clinical criteria. He or she can bypass the delay often apparent with calling for help through a hierarchy of medical and nursing staff. This is seen even in experienced nurses, who in an Australian survey were found to be more likely to activate an MET [40]. Nurses are the most powerful and numerous allies of RRS.
Staff may be ashamed to call a medical emergency team The issue of professional pride or fear of blame has to be overcome. Activation of an MET does not imply that ward personnel are incapable or unwilling to manage the patient themselves. This aspect must be emphasised in educational and preparation sessions. Hospital administration supporting the MET system needs to engage all staff in a re-orientation from individual to system thinking [41]. Policies should be widely available and regularly reinforced and communicated by senior hospital staff. As data collection and audits are part of the feedback arm of the MET [29], positive action should be taken to encourage favourable staff behaviour.

\section{Ward monitoring needs constant improvement}

Several studies have shown a circadian pattern of activation of MET [42-44]. This peculiar variation is most likely explained by the interaction between ward staff caring for the patient and the monitoring tools used. Such variation is absent in the ICU, where more extensive monitoring and a higher nurse/patient ratio are standard [43]. Recordings of early signs of critical conditions were 7.7 times more frequent than late signs, with nurses accounting for $86.1 \%$ of these [45]. Interestingly, in that study, $17.8 \%$ of all recordings of early signs and $9 \%$ of late signs were judged by nurses to be 'usual for the patient'. These commonly included mild hypoxaemia, hypercarbia, and hypotension. As the MET call criteria depend heavily on physiological alteration of signs, poor monitoring equipment, methods, and recognition by staff may be a major stumbling block in improving outcomes and RRS performance. Regular staff educational programs and audits of technology and processes of care are necessary to minimise these problems.

\section{Major delays in calling a medical emergency team}

Despite positive attitudes toward the MET system, nurses may not always follow the predetermined MET activation criteria or may fail to recognise when assistance is required. Daffurn and coworkers [46] showed, in a study conducted 2 years after implementation of an MET system, that nurses variably correctly identified scenarios warranting an MET call in $17 \%$ to $73 \%$ cases. Hypotension did not appear to alert nurses to summon assistance, and some nurses would still call a resident rather than the MET in the presence of severe deterioration and patient distress. Unpublished data from our experience confirm that delays in calling an MET are associated with increased in-hospital mortality (Figure 1) and that even a minor delay has a substantial effect on outcome. These observations highlight another challenge in the adoption and research of such systems. If deficient MET systems are tested, they may fail to show a clinical benefit. No matter how good the system is, major methodological challenges need to be overcome to evaluate such systems in a rigorous and clinically relevant way.

\section{Evaluating the medical emergency team system} Medical technologies and drugs are assessed using methodology favouring the statistical power of large numbers 
Figure 1

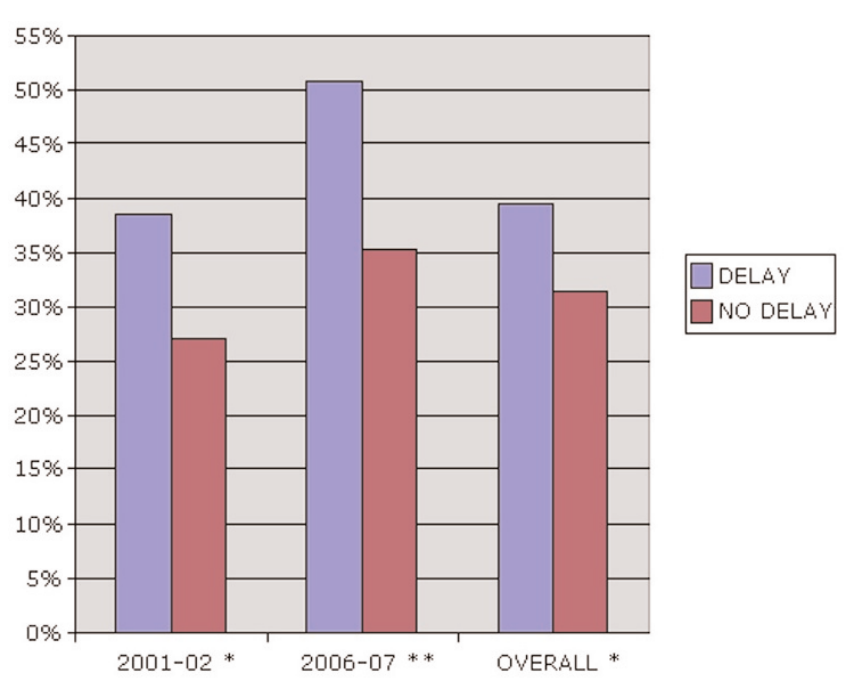

The effect of delay in medical emergency team (MET) calls on mortality in two cohorts of patients at the start of an MET program and 5 years later. ${ }^{*} p<0.001 ;{ }^{* *} p<0.004$.

and certain study designs. This approach dismisses real-life relevance, Bayesian logic, and common sense as too biased and methodologically flawed. Though scientifically valid, this approach fails to achieve a balance between rigour and reallife evidence in assessing process improvement [33]. The effectiveness of the MET is related to a systematic change in the way hospitals deliver care. An alternative, 'pragmatic science' approach by Berwick [47] promotes tracking effects over time, integrating detailed process knowledge into the work of interpretation, using small samples and short experimental cycles of change, and using multifactorial designs in evaluating system change. According to this paradigm, common sense practices like bringing critical care expertise to acutely ill ward patients might not require randomised controlled trials and other evidence-based methodology before incorporation into practice. We note that no randomised multicentre double-blind controlled trials exist to test the effectiveness of hand-washing by doctors and nurses.

Even if one intended to conduct a randomised controlled trial of METs within an institution, this would be made nearly impossible by the Hawthorne effect [48]. This effect would artificially lead to an improvement in the care of control patients, with doctors and nurses imitating the intervention being studied. It is also unethical to randomly assign acutely ill patients, as it would deny potentially life-saving interventions to those randomly assigned to 'placebo'. Adequately matched case-control studies, though not considered sufficiently rigorous, may avoid some of the shortcomings [49]. As a consequence, only hospitals can become the unit of randomisation (cluster randomisation) [50]. In the largest cluster randomised study of METs [51], the Medical Emergency Response Improvement Team (MERIT) study, investigators randomly assigned participating hospitals to standard care or the introduction of an MET. The result was an increased overall MET calling rate in MET hospitals but no substantial effect on cardiac arrest, unplanned ICU admissions, or unexpected death. However, that study had major shortcomings from severe lack of statistical power due to the large variance in outcome incidence and wide standard deviation and the lower-than-expected incidence of the outcome measures under investigation. Given the incidence and variance of such outcomes, more than 100 hospitals would have been needed to show a $30 \%$ difference in the composite outcome, whereas only 23 hospitals were actually recruited. Inadequate and non-uniform implementation of the MET was also an issue in MERIT as there was a lack of a continued educational process throughout the study period. Furthermore, the call rate in MERIT was much lower $(<20 \%)$ than that seen in hospitals implementing successful MET programs. This is not surprising as the evaluation time was only 6 months. Typically, such systems require more than a year or two to mature.

\section{Before-and-after studies}

The current literature on MET shows many examples of before-and-after studies dealing with single-centre data [52-56]. Inherent within this type of evidence is the lack of rigour and generalisability. Furthermore, the magnitude of the effect of the MET may be influenced by institution-specific administrative features and policies. Buist and coworkers [52] showed a 50\% reduction in the incidence of cardiac arrests, whereas a study by DeVita and colleagues [54] reported a 17\% decrease. Data from our institution [53] revealed a $65 \%$ relative risk reduction in a 4-month comparison study in surgical patients. Of note, almost all studies point to an effect of the MET in reducing cardiac arrests. The type of patients evaluated does appear to differ in outcomes, with surgical postoperative cases benefiting the most in terms of mortality reduction [55,56]. Despite methodological shortcomings, the MET has proliferated in hospitals, although controversy continues over whether it should be a standard of care (Table 2). Even if one believed in the concept of MET, adopting the MET poses major political and logistic challenges. One has to convince colleagues, educate nurses and doctors, maintain awareness, and ensure collegiality and performance [34,57-59]. Time is needed for the MET concept to 'bed in' [58] in order to reap its benefits in a substantial manner. Repeated education and periodic assessment of site-specific obstacles to utilisation of MET should be addressed [59]. If education and staff awareness can be maintained after the initial introduction, the MET system continues to increase in efficacy. Short-term studies may therefore underestimate its impact [34]. RRSs with their MET components are not easy, nor are they simple. Yet, they are worth the effort. 
Table 2

Research difficulties with the rapid response system
Difficulties with researching the rapid response system
Dismisses real-life relevance and common sense
Dependence of randomised trial methodology on numerical
strength, which requires patient randomisation
Hawthorne effect improves outcomes in control patients
Unethical to randomly assign patients to 'placebo'
Cluster randomisation of hospitals requires large numbers of
centres
Before-and-after studies lack rigour and generalisability

\section{Gaps and knowledge and future research}

Our understanding of the issues that surround RRSs is very limited. Only a few studies have been conducted in even fewer centres. The gaps in our knowledge define the future research agenda. We know little about the epidemiology of abnormal vital signs in hospital patients and the outcome of patients who experience them. We know little about the specificity and sensitivity of specific vital sign abnormalities and/or of clusters of such signs. We do not know whether improved monitoring technology with increased automation of vital sign recording and with advisory response systems can decrease adverse events or improve team activation. We do not know about the anthropology and psychology of how nurses and doctors currently respond to changes in patient status and why they do or do not activate RRSs. We do not know what teams do at the bedside which is useful and what they do at the bedside which is not useful. We have very little information on how such teams affect the issuing of not-forresuscitation orders in ward patients who are acutely ill. We have limited knowledge of how such systems might affect surgical patients differently from medical patients and how activation may occur differently in different specialty areas. In short, the gaps in our knowledge are wide and the research agenda equally big. Yet the process has just begun and there is growing momentum in terms of clinical application and investigation. It is likely that, once critical care physicians realise this is a new frontier for the specialty, we will be able to start filling these gaps step by step.

\section{Conclusion}

Translating common sense into evidence for a complex intervention like MET poses enormous challenges, and only progressive accumulation of evidence from different settings and situations will ultimately sway physician behaviour. A conclusive randomised controlled trial is unlikely to occur. Medical leadership needs to acknowledge the fact that acutely ill patients in the wards should be identified rapidly and that critical care expertise, resources, and personnel should be delivered to the bedside of the critically ill wherever

\section{This article is part of a review series on Translational research, edited by John Kellum.}
Other articles in the series can be found online at http://ccforum.com/articles/ theme-series.asp?series=CC_Trans

they are. In the words of the slogan of the American Society of Critical Care Medicine, we need to deliver the 'right care, right now'. Hospital wards should be no exception.

\section{Competing interests}

The authors declare that they have no competing interests.

\section{References}

1. Brennan TA, Leape LL, Laird NM, Hebert L, Localio AR, Lawthers AG, Newhouse JP, Weiler PC, Hiatt HH: Incidence of adverse events and negligence in hospitalised patients: results of the Harvard Medical Practice Study I. N Engl J Med 1991, 324: 370-376.

2. Leape LL, Brennan TA, Laird N, Lawthers AG, Localio AR, Barnes BA, Hebert L, Newhouse JP, Weiler PC, Hiatt $\mathrm{H}$ : The nature of adverse events in hospitalized patients: results of the Harvard Medical Practice Study II. N Engl J Med 1991, 324:377-384.

3. Baker GR, Norton PG, Flintoft V, Blais R, Brown A, Cox J, Etchells E, Ghali WA, Hébert P, Majumdar SR, et al:: The Canadian Adverse Events Study: the incidence of adverse events among hospital patients in Canada. CMAJ 2004, 170:1678-1686.

4. McGlynn EA, Asch SM, Adams J, Keesey J, Hicks J, DeCristofaro A, Kerr EA: The quality of health care delivery to adults in the United States. N Engl J Med 2003, 348:2635-2645.

5. Wilson RM, Runciman WB, Gibberd RW, Harrison BT, Newby L, Hamilton JD: The quality in Australian health care study. Med J Aust 1995, 163:458-471.

6. McQuillan P, Pilkington S, Allan A, Taylor B, Short A, Morgan G, Nielsen M, Barrett D, Smith G: Confidential inquiry into quality of care before admission to intensive care. BMJ 1998, 316: 1853-1858.

7. Hershey CO, Fisher L: Why outcome of cardiopulmonary resuscitation in general wards is poor. Lancet 1982, 1:31-34.

8. Emergency Care Research Institute (ECRI): Rapid response teams improve quality/safety. The Risk Management Reporter 2006, 25:1-9.

9. Dumot JA, Burval DJ, Sprung J, Waters JH, Mraovic B, Karafa MT, Mascha EJ, Bourke DL: Outcome of adult cardiopulmonary resuscitations at a tertiary referral center including results of 'limited' resuscitations. Arch Intern Med 2001, 161:1751-1758.

10. Sandroni C, Nolan J, Cavallaro F, Antonelli M: In-hospital cardiac arrest: incidence, prognosis and possible measures to improve survival. Intensive Care Med 2007, 33:237-245.

11. Paniagua D, Lopez-Jimenez F, Londoño JC, Mangione CM, Fleischmann K, Lamas GA: Outcome and cost-effectiveness of cardiopulmonary resuscitation after in-hospital cardiac arrest in octogenarians. Cardiology 2002, 97:6-11.

12. Schein RM, Hazday N, Pena M, Ruben BH, Sprung CL: Clinical antecedents to in-hospital cardiopulmonary arrest. Chest 1990, 98:1388-1392.

13. Kause J, Smith G, Prytherch D, Parr M, Flabouris A, Hillman K: Australian and New Zealand Intensive Care Society Clinical Trials Group. A comparison of antecedents to cardiac arrests, deaths and emergency intensive care admissions in Australia and New Zealand, and the United Kingdom-The ACADEMIA study. Resuscitation 2004, 62:275-282.

14. Buist MD, Jarmolowski E, Burton PR, Bernard SA, Waxman BP Anderson J: Recognising clinical instability in hospital patients before cardiac arrest or unplanned admission to intensive care. A pilot study in a tertiary-care hospital. Med J Aust 1999, 171:22-25. 
15. Franklin C, Matthew J: Developing strategies to prevent inhospital cardiac arrest: analysing response of physicians and nurses in the hours before the event. Crit Care Med 1994, 22: 244-247.

16. Smith AF, Wood J: Can some in-hospital cardio-respiratory arrests be prevented? A prospective survey. Resuscitation 1998, 37:133-137.

17. Goldhill DR, White SA, Sumner A: Physiological values and procedures in the $24 \mathrm{~h}$ before ICU admission from the ward. Anaesthesia 1999, 45:529-534.

18. Goldhill DR, McNarry AF: Physiological abnormalities in early warning scores are related to mortality in adult inpatients. $\mathrm{Br} J$ Anaesth 2004, 92:882-884.

19. Garrard C, Young D: Suboptimal care of patients before admission to intensive care is caused by a failure appreciate or apply the ABCs of life support. BMJ 1998, 316:1841-1842.

20. Hillman KM, Bristow PJ, Chey T, Daffurn K, Jacques T, Norman SL, Bishop GF, Simmons G: Antecedents to hospital deaths. Intern Med J 2001, 31:343-348.

21. Hillman KM, Bristow PJ, Chey T, Daffurn K, Jacques T, Norman SL, Bishop GF, Simmons G: Duration of life-threatening antecedents prior to intensive care admission. Intensive Care Med 2002, 28:1629-1634.

22. Nurmi J, Harjola VP, Nolan J, Castrén M: Observations and warning signs prior to cardiac arrest. Should a medical emergency team intervene earlier? Acta Anaesthesiol Scand 2005, 49:702-706.

23. Saklayen M, Liss H, Makert R: In-hospital cardiopulmonary resuscitation. Medicine 1995, 74:163-175.

24. Peberdy MA, Kaye W, Ornato JP, Larkin GL, Nadkarni V, Mancini ME, Berg RA, Nichol G, Lane-Trultt T: Cardiopulmonary resuscitation of adults in the hospital: a report of 14720 cardiac arrests from the National Registry of Cardiopulmonary Resuscitation. Resuscitation 2003, 58:297-308.

25. Fresco C, Carinci F, Maggioni AP, Ciampi A, Nicolucci A, Santoro E, Tavazzi L, Tognonia G: Very early assessment of risk for inhospital death among 11,483 patients with acute myocardial infarction. GISSI investigators. Am Heart J 1999, 138:10581064.

26. Nardi G, Riccioni L, Cerchiari E, De Blasio E, Gristina G, Oransky M, Pallotta F, Ajmone-Cat C, Freni C, Trombetta S, et al.: Impact of an integrated treatment approach to the severely injured patients (ISS $>16$ ) on hospital mortality and quality of care. Minerva Anesthesiol 2002, 68:25-35.

27. Rivers E, Nguyen B, Havstad S, Ressler J, Muzzin A, Knoblich B, Peterson E, Tomlanovich M; Early Goal-Directed Therapy Collaborative Group: Early goal-directed therapy in the treatment of severe sepsis and septic shock. $N$ Engl J Med 2001, 345: 1368-1377

28. Aneman A, Parr M: Medical emergency teams: a role for expanding intensive care? Acta Anaesthesio/ Scand 2006, 50: 1255-1265.

29. DeVita MA, Bellomo R, Hillman K, Kellum J, Rotondi A, Teres D, Auerbach A, Chen WJ, Duncan K, Kenward G, et al:: Findings of the First Consensus Conference on Medical Emergency Teams. Crit Care Med 2006, 34:2463-2478.

30. Jones D, Duke G, Green J, Briedis J, Bellomo R, Casamento A, Kattula A, Way M: Medical Emergency Team syndromes and an approach to their management. Crit Care 2006, 10:R30.

31. Winters BD, Pham J, Provonost PJ: Rapid response teamswalk, don't run. JAMA 2006, 296:1645-1647.

32. Winters BD, Pham JC, Hunt EA, Guallar E, Berenholtz S, Pronovost PJ: Rapid response systems: a systematic review. Crit Care Med 2007, 35:1238-1243.

33. DeVita MA, Bellomo R: The case of rapid response systems: are randomized clinical trials the right methodology to evaluate systems of care? Crit Care Med 2007, 35:1413-1414.

34. Jones D, Bellomo R, Bates S, Warrillow S, Goldsmith D, Hart G, Opdam H, Gutteridge G: Long term effect of a medical emergency team on cardiac arrests in a teaching hospital. Crit Care 2005, 9:R808-R815

35. Jones $\mathrm{D}$, Bellomo $\mathrm{R}$ : Introduction of a rapid response system: why we are glad we MET. Crit Care 2006, 10:121.

36. Jones D, Baldwin I, Mclntyre T, Story D, Mercer I, Miglic A, Goldsmith D, Bellomo R: Nurses' attitudes to a medical emergency team service in a teaching hospital. Qual Saf Health Care 2006, 15:427-432
37. DeVita M: Medical emergency teams: deciphering clues to crises in hospitals. Crit Care 2005, 9:325-326.

38. Braithwaite RS, DeVita MA, Mahidhara R, Simmons RL, Stuart S Foraida $\mathrm{M}$, and members of the Medical Emergency Response Improvement Team (MERIT): Use of medical emergency team (MET) responses to detect medical errors. Qual Saf Health Care 2004, 13:255-259.

39. Galhotra S, Scholle CC, Dew MA, Mininni NC, Clermont G, DeVita MA: Medical emergency teams: a strategy for improving patient care and nursing work environments. $J$ Adv Nurs 2006, 55:180-187.

40. Salamonson $Y$, van Heere $B$, Everett $B$, Davidson P: Voices from the floor: Nurses' perceptions of the medical emergency team. Intensive Crit Care Nurs 2006, 22:138-143.

41. Cretikos MA, Parr MJA: The medical emergency team: 21st century critical care. Minerva Anestesiol 2005, 71:259-263.

42. Jones D, Bates S, Warrillow S, Opdam H, Goldsmith D, Gutteridge G, Bellomo R: Circadian pattern of activation of the medical emergency team in a teaching hospital. Crit Care 2005, 9:R303-R306.

43. Galhotra S, DeVita MA, Simmons RL, Schmid A: Impact of patient monitoring on the diurnal pattern of medical emergency team activation. Crit Care Med 2006, 34:1700-1706.

44. Jones D, Bellomo R, Bates S, Warrilow S, Goldsmith D, Hart G, Opdam $\mathrm{H}$ : Patient monitoring and the timing of cardiac arrests and medical emergency team calls in a teaching hospital. Intensive Care Med 2006, 32:1352-1356.

45. Harrison GA, Jacques TC, Kilborn G, McLaws ML: The prevalence of recordings of the signs of critical conditions and emergency responses in hospital wards - the SOCCER study. Resuscitation 2006, 65:149-157

46. Daffurn K, Lee A, Hillman KA, Bishop GF, Bauman A: Do nurses know when to summon emergency assistance? Intensive Crit Care Nurs 1994, 10:115-120.

47. Berwick DM: Broadening the view of evidence-based medicine. Qual Saf Health Care 2005, 14:315-316.

48. Parsons HM: What happened at Hawthorne? Science 1974 183:922-932.

49. Cretikos M, Chen J, Hillman K, Bellomo R, Finfer S, Flabouris A: The objective medical emergency team activation criteria: a case-control study. Resuscitation 2007, 73:62-72.

50. Bristow PJ, Hillman KM, Chey T, Daffurn K, Jacques TC, Norman SL, Bishop GF, Simmons GE: Rates of in-hospital arrests, deaths and intensive care admissions: the effect of a medical emergency team. Med J Aust 2000, 173:236-240.

51. Merit study investigators: Introduction of the medical emergency team (MET) system: a cluster-randomised controlled trial. Lancet 2005, 365:2091-2097.

52. Buist MD, Moore GE, Bernard SA, Waxman BP, Anderson JN Nguyen TV: Effects of a medical emergency team on reduction of incidence of and mortality from unexpected cardiac arrests in hospital: preliminary study. BMJ 2002, 324:1-6.

53. Bellomo R, Goldsmith D, Uchino S, Buckmaster J, Hart GK, Opdam H, Silvester W, Doolan L, Gutteridge G: A prospective before-and-after trial of a medical emergency team. Med $J$ Aust 2003, 179:283-287.

54. DeVita MA, Braithwaite RS, Mahidhara R, Stuart S, Foraida M Simmons RL; Medical Emergency Response Improvement Team (MERIT): Use of medical emergency team responses to reduce hospital cardiopulmonary arrests. Qual Saf Health Care 2004, 13:251-254.

55. Bellomo R, Goldsmith D, Uchino S, Buckmaster J, Hart G, Opdam $\mathrm{H}$, Silvester W, Doolan L, Gutteridge G: Prospective controlled trial of effect of medical emergency team on postoperative morbidity and mortality rates. Crit Care Med 2004, 32:916-921.

56. Jones D, Egi M, Bellomo R, Goldsmith D: Effect of the medical emergency team on long-term mortality following major surgery. Crit Care 2007, 11:R12.

57. Jones D, Bates S, Warrillow S, Goldsmith D, Kattula A, Way M Gutteridge G, Buckmaster J, Bellomo R: Effect of an education programme on the utilization of a medical emergency team in a teaching hospital. Intern Med J 2006, 36:231-236.

58. Kenward G, Castle N, Hodgetts T, Shaikh L: Evaluation of a medical emergency team one year after implementation. Resuscitation 2004, 61:257-226.

59. Jones DA, Mitra B, Barbetti J, Choate K, Leong T, Bellomo R: Increasing the use of an existing medical emergency team in a teaching hospital. Anaesth Intensive Care 2006, 34:731-735. 